\title{
Reflections on Doing Research Grounded in My Experience of Perinatal Loss: From Auto/biography to Autoethnography
}

\author{
by Deborah Davidson \\ York University, Toronto
}

Sociological Research Online, 16 (1) 6

<http://www. socresonline.org.uk/16/1/6.html>

$10.5153 /$ sro.2293

Received: 7 Jan 2009 Accepted: 30 Jan 2011 Published: 28 Feb 2011

\begin{abstract}
This article, derived from my doctoral dissertation (Davidson 2007) examining the emergence of hospital protocols for perinatal bereavement during the last half of the twentieth century in Canada, focuses on the methodological complexities - the draw, the drain, and the delight of doing qualitative research grounded in my own experience of perinatal loss. With my dissertation now a fait a complete, reflecting back on my research, my use of autoethnography at this point allows a return to a story that has already happened and involves 'the construction and reconstruction' of my personal experiences as narratives' (Autrey 2003: 10). Taking this narrative turn, my enquiry here shifts auto/biography to autoethnography as a mode of enquiry.
\end{abstract}

\section{Keywords: Qualitative Research; Feminist Research; Perinatal Loss and Grief; Bereavement; Experience; Auto/biography; Autoethnography}

\author{
Introduction
}

\begin{abstract}
The most persuasive sociological writing emerges from a personal feeling. Whether it be of anger or delight, it forms a conviction about something good or bad in society. It unfolds into a story of loss and change, protest or revolution, and then develops into something more abstract, ecumenical, and systematic but recognizably spoken nonetheless, by a voice still breaking with the emotion that first fired it into the world (Williams 2001: 123).
\end{abstract}

1.1 My experience of perinatal loss led me to my doctoral research in Sociology, to understanding of the emergence of hospital-based bereavement protocols for perinatal death (the death of a fetus or baby during pregnancy or around the time of birth). In this article I discuss the challenges and complexities of doing that research - the why and how, my framework for thinking, my hybrid (auto/biographical-feministgrounded) methodology, and my post research reflection through the use of autoethnography. First, I provide a brief social, historical, and institutional background to the dissertation study, a general overview of the research approach, and a brief description of the hospital protocols. Then I move to a discussion of the elements of conducting research emerging from my own experience of perinatal loss prior to the hospital protocols. Here, I shift to personal narrative in the form of autoethnography.

\section{Social, Historical, and Institutional Background to the Study of the Emergence of Hospital Protocols for Perinatal Bereavement}

2.1 It is estimated that in North America $20 \%$ to $30 \%$ of all pregnancies end in loss (Layne 1996, 1992, 1990; Van and Meleis 2003; Farr et al. 2007). In many cases, the reasons for perinatal loss are unknown. What is known is that the use of assisted reproductive increases rates of perinatal loss, particularly miscarriage (Zádori 2006; Schieve et al. 2003; Langen et al. 2010). As well, poverty has significant consequences pregnancy outcomes and maternal health (Hodnett et al. 2009; Whitehead et al. 2009; Kavanaugh and Hershberger 2005; Bolig et al. 1999). And in North America, women of non-Euro-AmericanCanadian ethnicity are more likely to experience perinatal loss (Kitsantas 2008; Kavanaugh and Hershberger 2005; Arias et al. 2003). Research conducted since the 1980s recognizes many women grieve losses at all stages of gestation (Fetus and Newborn Committee 1983; Layne 1997, 1996, 1992, 1990; Letherby 1993; Lovell 1983; Malacrida 1999, 1998; Reinharz 1988; Slade and Cecil 1994). It is also 
important to note that it is not unusual for women to grieve the voluntary loss of unplanned and unwanted pregnancies (Williams 2006; Coleman 2004).

2.2 The meaning of perinatal loss was made and remade in Canada's hospitals during the second half of the twentieth century. Until about the mid 1980s the death of an unborn or newborn was usually managed without the institutional recognition of maternal grief, which is understood here as 'a mother's highly variable emotional, psychological, physical, and social response to the involuntary loss of her fetus or infant' (Peppers 1989: 135, citing Peppers and Knapp 1980: 155). When hospital childbirth became a general social norm in Canada, the hospital had considerable control over women's childbirth experiences (Mitchinson 2002). Generally, women were sedated and quickly separated from their dying or dead babies, and the grief they may have experienced was silenced (Leon 1992; Peppers and Knapp 1980; Sudnow 1967). Women were told, by health care professionals and others, such things as 'forget about it', and 'have another one'; not appreciating that many women grieve their loss, that they didn't forget the experience or their child, and that one child would not simply replace another (Peppers and Knapp 1980; Borg and Lasker 1982; Kirkley-Best et al. 1985; Rowe et al. 1978; Wolff et al. 1970; Schreiner et al. 1979).

2.3 In my discussion of the emergence of hospital bereavement protocols for perinatal loss, I argue that while social and historical factors such as changing attitudes around death and grief, and changes in technology and medical specialization in hospitals conditioned the shift in hospital practices for perinatal death, it was a subset of health care providers who, first through individual agency and then collective action, formed the critical mass required to develop and actuate the change. Collective action occurred in a hospital culture of medicalization, specialization, and high technology. Ironically, it is in part because of the distancing effects of medicalization and technology on the caregiver-patient relationship that the protocols emerged. As pregnancy and childbirth were further medicalized and increasingly subject to medical technology distancing caregivers from birthing women and their dead or dying babies, some caregivers repositioned themselves closer to women and their experiences of grief. (Davidson 2007)

2.4 It was not until the mid 1980s that saw the beginnings of a shift in the standard of care for women experiencing perinatal loss. Briefly, I note three historical conditions that contributed to the "discovery" of perinatal loss as bereavement and laid the broader conditions for the emergence of the protocols. First, the 1950s saw the invention of the "perinatal interval" in aid of reducing the rates of perinatal mortality. This was complemented by the development of related medical technologies and specialization in the 1960s and 1970s. Second, the development of psychological and social science literatures of the 1960s through the 1980s on death, loss, and attachment created a neo-modern model of death, which would be put into action by innovative caregivers. Third was the emergence of pregnancy loss support groups that brought voice to women's grief.

2.5 Prior to medical developments in the mid-twentieth century, infants considered too weak to survive were left without treatment (Anspach 1993). Beginning in the 1950s, a pronatalist ideology, according to Deborah Findlay (1993), suffused obstetric and gynaecologic knowledge. In the 1960s development of neonatal intensive care, 'signaled a dramatic transformation to a treatment philosophy of active, aggressive intervention' (Anspach 1993: 3). While the reduction of perinatal mortality became the central interest of maternal and child health care in the West (Weir 2006), it was a bitter irony and an institutional contradiction that the grief experienced by many women whose fetuses and neonates died received little or no recognition or support during this time.

2.6 Discussing changes in our understanding of death, sociologist Tony Walter (1994) details specific features of what he terms a shift from modern to neo-modern death practices that coincide with the period in which the perinatal bereavement protocols emerged. Walter's (1994: 204) notion of the "revival of death" in the neo-modern period where modern medicine and more traditional elements of death are combined for a "more personal way of death, disposal and/or grief". It is in this historic shift from modern to neo-modern death that hospital protocols for perinatal bereavement emerged, personalizing death in a period of increased medicalization and intensified technology.

2.7 Through a profound shift in understanding and practice, by the later 1990s, it became the institutional expectation that women who suffered the death of an unborn or newborn fetus or baby would often experience the death as a loss and, in the interest of maternal health, it was the duty of hospitals to recognize and respond to the grief experienced by these women. When hospitals began to recognize a need for supportive health care interventions for perinatal loss they also recognized that women would need support after they left the hospital. This was accomplished in part through peer support groups. Pregnancy loss support groups, which grew out of the death awareness movement of the 1960s and the self-help movement of the 1970s, emerged in the mid-1970s 'following one of the most significant periods of growth in psychology' (Layne 2003: 13). This shift to the institutional recognition of grief in perinatal loss occurred at a particular historic moment and was born of local innovation by key actors as they gave voice to women's grief (Davidson 2007).

2.8 Asking why these particular caregivers, as key actors, were innovators of change in hospitals. I argue that while the participants in this research were passionate in their roles as caregivers, it was the sentinel experiences in their lives that first sensitized them to the social-emotional needs of women who experienced perinatal death. From this position proximate to women and their grief, caregivers recognized women's needs that were not being met by the practice of separation and silence. And it was from this position that caregivers first heard women's stories and gave voice to their grief. (For further discussion see Davidson 2008.) Moreover, caregivers' emotional labour, managing their own and others' emotions, was a key determinant in the institutional change.

2.9 Engaged in a shift from a biomedical to a biopsychosocial model of care, the key actors were inspired by their passion and a sense of compassion. Their individual efforts were then elaborated through leadership and teamwork, which developed into the collective action needed to institute a new standard of 
care for perinatal loss. It should be noted that while the protocols involve checklists to facilitate communication among staff as to what bereavement care was included for each patient, fundamental to the protocols and relevant checklists, and consistent with family-centred childbirth in place in hospitals at the time the protocols developed, and continuing today, is the provision of choice, understanding not all women grieve and women who do grieve, grieve in a variety of ways.

\section{A General Overview of the Research Approach: Experience as Inspiration and a Hybrid Methodology}

3.1 My dissertation research is an intrinsic explanatory case study, providing a mesodomain symbolic interactionist account of the emergence of hospital-level recognition and management of perinatal bereavement to include 'the intersection of historical, structural, and action contexts' (Hall 2003: 37). Told through the lens of experience it was shaped by a hybrid of auto/biographical, feminist, auto/biographical, and grounded theory methodologies.

3.2 My lived experience of perinatal death as loss that I grieved, and my feminist perspective are fervently entwined. My feminist perspective, with analysis by, about, and for women, and those interested in providing compassionate health care for women who experience grief resulting from perinatal loss, affirms 'that the lives of women are important' (Rothman 1987: 239), and that women's experiences of grief in perinatal loss have been silenced. (See, as examples, the work of Braun and Berg 1994; Cecil 1996a, 1996b; Hebert 1998; Layne 2003, 1997, 1996, 1992, 1990; Letherby 1993; Malacrida 1999, 1998; Rajan and Oakley 1993; Simonds and Rothman 1992.) Feminist anthropologist, Linda Layne (2003: 239), for example, has argued that feminists 'have not only abandoned their sisters in their hour of need, they have contributed to the shame and isolation that attends these events' by surrendering 'the discourse of pregnancy loss to antichoice activists'. She calls feminists to 'acknowledge the frequency and import of such events in women's lives and create a women-centered discourse of pregnancy loss' (Layne 2003: 239).

3.3 My experiences of perinatal loss and my feminist perspective colour and inform my use of grounded methodology. In their discussion of grounded theory, Anselm Strauss and Julie Corbin (1994: 283) point out that the development of a grounded methodology includes 'adaptation' by combining it with other methodologies. Here, I make such an adaptation as I use auto/biographical and feminist experiential methodologies as a modification to, or a hybrid of, a more orthodox grounded methodology.

3.4 Purposive sampling led me to thirty-five interviews, with key actors in the change, were held primarily between 2003 and 2004, and represented several hospitals in Southern and South Western Ontario. Some of the participants were also involved in documenting the protocols in the 2000 Family-Centred Maternity and Newborn Care: National Guidelines. The key actors interviewed included primarily hospital caregivers nurses, chaplains, social workers, and physicians; also included were health care advocates, including women who had previously experienced perinatal death.

\section{A Brief Description of the Protocols}

4.1 Perinatal bereavement protocols are health care interventions; they are policies and practices that recognize and respond to women's social-emotional needs in perinatal loss. While the term "protocol" is typically referred to as a written text, I use the term here to include both written and unwritten changes in practice. The protocols are not simply a normative standard that appears in textual form; rather, they are local, dynamic, embodied work practices that coordinate a series of social relations and that respond to individual situations. The emergence of these protocols recognized and institutionally constituted the experience as perinatal loss, as bereavement experienced by many, where bereavement identifies the objective situation of individuals who have experienced loss.... In short a bereaved person is one who has been deprived, robbed, plundered or stripped of something (Katz 2001: 5, citing Corr et al. 1997: 220).' The words of a hospital chaplain whom I interviewed for this research reflect the reasons for the emergence of the hospital protocols:

When you enter into the experience of perinatal death you try to make a story to deepen your understanding of what this brief life was rather than pushing it away. You think of that short space of time as a full life. And you look into it to find its value and the gift that that baby offered to the world, brought into the world, and you honour that life in its fullness, even though it was brief.... It used to be understood that this experience needed to be left behind, but we discovered that people didn't leave it behind, that they carried it with them the rest of their lives. [chaplain, \#20]

These words also resonate with my attempt to make sense out of my own experience - and to weave a sociological story around it.

4.2 Chapter 8, "Loss and Grief", of the 2000 Family-Centred Maternity and Newborn Care: National Guidelines (Health Canada 2000), distributed Canada-wide as a guide to practice, gives the perinatal bereavement protocols substantial force nationally. The Guidelines were the result of a three-phase process - starting with a survey of users; proceeding with consultation with national professional and consumer organizations; and concluding with the writing and review being accomplished by individuals representing the various disciplines involved in maternal and newborn care, families and all regions of the country (Health Canada 2000: v). More than a change in Canada's hospitals, it should also be noted that for late fetal deaths:

the provision of an empathetic caring environment, and strategies to enable the mother and family to accept the reality of death, are now part of the standard of nursing and social support in most of the developed world (Fox 1997, et al., cited in Chambers and Chan 2004: 2). 
4.3 The protocols, as interventions for responding to women's social-emotional in perinatal loss, are categorized as supportive, facilitative, and informational, which often co-occur in practice. Supportive interventions demonstrate a caregiver-patient relation intended primarily to help women with feelings of grief. Facilitative interventions intercede on behalf of women as they describe relations both among caregivers and of caregivers and institutions. Connecting women with texts and organizations outside of the hospital, informational interventions enable families to make decisions and regain a sense of control during their experience of grief. Of key importance is that the protocols offer choice, and thus that women receive the information necessary to understand their options.

\section{A Narrative Turn to Autoethnography - I Never Remember Believing in Santa Claus: Reflections on Doing Research Grounded in Personal Experience}

5.1 In a significant way, my research for this project began even before I experienced my own losses. Even as children, we come to learn what, in the world close to us, is important and valued positively or negatively by others. Infant deaths were hushed, hidden; Santa Claus was real. Experience is best understood in retrospect and reflection, and experience for this research was my inspiration. It was at the intersection of auto/biography - my autobiography and the biographies of key actors interviewed and the women involved - and history that this work was inspired, was carried out, and is analyzed. This approach recognizes the importance of 'intellectual biography' (Letherby 2000: 94), and starts 'from the aim of making sociological sense of the self - one's own history, development and biography' (Letherby 2003: 1). With my dissertation as a fait a complete, my enquiry shifts now to a more personal, vulnerable intimacy (Ellis and Bochner 2006), using autoethnography as a mode of enquiry.

5.2 The what's, why's and how's of autoethnography are debated in the literature. (For an example of interesting discussion on this debate see the Journal of Contemporary Ethnography, 2006, Vol. 35, No. 4.) Autoethnography is often referred to as a genre of autobiography or a 'blurred genre' (Maguire 2006), and a 'hybrid form of autobiography' (Autrey 2003, citing Watson 1997: 7). Reflecting back on my research, my use of autoethnography at this point allows a return to a story that has already happened and involves "the construction and reconstruction" of my personal experiences as narratives' (Autrey 2003: 10). And while I have cautiously and successfully traversed its paths in my dissertation, and I am ready for what Carolyn S. Ellis and Arthur P. Bochner call an 'unruly, dangerous, vulnerable, rebellious, and creative' (Ellis and Bochner 2006: 443) mode of enquiry. Here, I take my hand, head and heart, on a sharper narrative turn.

5.3 This story, as I tell it here, my story, begins with a phantasm - Santa Claus. I never remember a time when I believed in Santa Claus. My earliest memory of him, at about age three or four, was pretending to believe in him, or in the idea of him, so as not to displease my parents. The idea of Santa was too simple; much was left unexplained, or worse - ill explained. This is not an unhappy memory; it did not leave me feeling that I had missed something important. Rather it was, perhaps, one of my earliest introductions into the delights of the complexity of being human. The second time pretence became an issue in my life was after the births and deaths of my babies.

5.4 In 1975 and 1977 I gave birth to premature babies who were whisked away before I could see them, or likely so I would not see them either alive or dead. They were phantasms of another sort, or so it would seem. Even though my son, born in 1975 at 29 weeks gestation, lived for ten hours, I did not see him. I learned of his death when I was moved to a room where I would not make yet-to-deliver women

uncomfortable. Even at that point, they did not tell me, but I knew. My daughter, born in 1977 at 27 weeks gestation, died in the delivery room shortly after her birth. It would have been so easy for them to give me at least a glimpse, perhaps even let me hold her. But they did not. Official forms regarded their birth, death, and disposal. Yes, 'disposal,' in the parlance of the hospital. The forms were given to my children's father to be filled out with the help, the "guidance", of the hospital staff - Baby Whatley was sufficient they said. I had no opportunity to name my babies for public record. They were cremated in the hospital and disposed of without invitation or ceremony. Hushed and hidden - ghost babies - phantasms.

5.5 One of my clearest and coldest memories of my losses, on both occasions, was leaving the hospital with nothing to take away - no baby in my body; no baby in my arms. This, like many other particular memories, is embodied deeply. I can feel it; I can smell the outdoor air on the days I stepped out of the hospital without my children. The only "official" documentation of their lives, for me, is in the form of the autopsy reports I received at my insistence many years after their births/deaths. I was provided with no mementos, no tangible evidence of their existence - phantasms. But my research and dissertation are real - remaking my experience and my babies real - Jason and Mary - Real.

5.6 I was told I was young and could have another "one". I was dismissed from hospital as if I had never given birth, as if I would not experience grief. But the grief was real, and so were my babies. Soon after the birth-death of my son a public health nurse called me at home to see how my baby was doing. After the birth-death of my daughter no one called. For the next twenty years I grieved alone and in silence - a birth mother-death mother.

5.7 While I felt as though I were imploding, the face I presented to the world was of a woman "doing fine", "getting over it". I knew the rules; I had always been a "good girl", not wanting to be unruly or rebellious, to cause others' distress. But unlike my Santa Claus memory, this is an unhappy memory. The idea others had of my experience was too simple; much was left unexplained, or worse - ill explained. This memory leaves me feeling as if I missed something important, and it leaves me with a sense of shame - that I had been good, had not rebelled.

5.8 I experienced my losses as a young, white, middle class woman with a spouse. Years later, through research, I found that the reason my babies were born early was because my mother was prescribed the 
drug diethylstilbestrol (also known as DES) given predominantly to upper working, middle and upper class women who were "meant" to breed. Supposedly DES would prevent the miscarriage of me as a fetus. But this was a miscarriage - of justice. It was learned that the drug, the first synthetic estrogen, crossed the placenta and affected many of the developing fetuses, especially their reproductive tracts - and it did not prevent miscarriages. My cervix, as a result, has been declared "incompetent". My body failed us. Science and technology, human endeavours, failed us. Another reason to be angry. Although I was socialized to be a "good girl", knowing this, I directed my anger through feminist scholarship.

5.9 First needing a research topic for an undergraduate course in qualitative methods, I decided to explore women's experiences of perinatal death; for that I turned to a feminist perspective for answers and, as it happened, for validation. My M.A. research was on the drug diethylstilbestrol. Later, as questions answered led to more questions asked, my dissertation topic emerged. Borrowing from Shulamit Reinharz (2003: 253) this research project:

began deep within my psyche and body because [it] dealt with silence, with missing pieces, with what is not there. [It] proceeded by making the missing visible; [it] ended by breaking the silence and reshaping what we know.

5.10 My experiences of the birth and death gave me a researchable project for my dissertation - grounded my research, and helped me gain access to participants in my study. I decided that disclosure about my losses would likely help me secure interviews, that it was in keeping with a feminist ethic of full disclosure, and that it was genuine to my motivation for research. My auto/biography facilitated entry to the field and my credibility as a researcher in the eyes of the research participants. Had I not been familiar with and networked in women's maternal health issues, finding participants would have been much more difficult. I secured interviews with all too-busy-floor nurses, physicians, and high profile policy makers. The nurses in administrative positions whom I interviewed suggested I interview floor nurses who had much familiarity working with women who had experienced perinatal death; the administrators cleared the schedules of the floor nurses so that I could interview them while they were on duty. I believe that because I was able to approach the topic of managing perinatal loss, a topic dear to the research participants, with sensitivity and knowledge, I was more likely to obtain the interviews.

5.11 Questions I asked of the participants would likely have been elementary had I not been close to this topic. The participants seemed to enjoy the interviews and were always willing to allow me more time than I initially scheduled. I believe that I was trusted and respected as an interviewer in part because my experience made me sensitive to what was important to the research participants. As a feminist researcher I did not and do not claim objectivity (Letherby 2003).

5.12 Doing the interviews for this research was both the most draining and exhilarating part of this process. Actually, that wording appears in the dissertation. Upon reflection - rewind - the experiences that led to this research were, to say the least, the most draining. The research, however, would fill me up again impregnate me once more. It was the interview part of the research that my autobiography met the biographies of the participants. This research was, what Barbara Katz Rothman (1986), pointing to researching and writing about grief, calls 'hard work'. I savoured the interviews, but also wanted to cocoon myself for days after each. I was temporarily overwhelmed, which reminded me again of the early pain of loss, where sleep was my relief. But as always, I rebound, and realized, with pride, that I had myself to thank for my revival and renewal - rebirth. Does this mean that I would not have benefitted from the protocols? I think not.

5.13 Not lured by an illusion of objectivity (see Emke 1996; Letherby 2003, Rothman 1986), I was constantly amazed at the people I interviewed, for their care and compassion, their determination, and their validation of experiences like mine. I felt privileged to interview them. I wondered if I was able to tell this story without sanctifying their efforts. But hanging on to myself as researcher, I always returned to my agenda to explain why and how, and to position these questions in the broader social and historical context, which allowed their efforts. My birth mother-death mother self, however, sees them as living, breathing saints - phantastic, not phantasmic.

5.14 Both auto/biography and authethnography have been accused of being self-indulgent and opportunistic. Was I, as a researcher, self-indulgent and opportunistic to use my experiences of loss and bereavement - of my babies? And if so, what have I gained and at what cost? Interestingly or perhaps ironically, I am using my position as a scholar to assuage my grief. Perhaps I am self-indulgent, as I am writing my present and my future with my past. And yes, this is opportunistic. I describe the bereavement protocols as an attempt to address the experience of loss and grief and integrate it into my life in a positive way. Not having had the opportunity for integration as a result of the silence and separation I experienced, I have created my own opportunity for integration, and in doing so I contribute to sociological scholarship, and to my academic career - and I rewrite my story. It is through this work that I have readdressed my experiences and repositioned myself as researcher, as I have integrated my experiences of loss into my life in a meaningful way, in a way that acknowledges, enfranchises, and thus redresses those losses.

\section{Conclusion}

6.1 I have described the complexity of doing this research grounded in personal experience. My experience of grief and my experience as a researcher are interwoven in the study I have described. As such, working through the methodological considerations for this project began prior to my recognition of them and will continue beyond this project's limits. According to D. Jean Clandinin and F. Michael Connelly (1994: 417) 'methods for the study of personal experience are simultaneously focused in four directions: inward and outward, backward and forward'. In my reflection, I have searched backward and inward to see my way 
forward, both in personal and scholarly pursuit. Upon more temporally distanced reflection, I tried my hand, along with my head and my heart, at an autoethnographic narrative to iterate the challenges and celebration of personal experience research.

\section{References}

ANSPACH, R. (1993). Deciding Who Lives: Fateful Choices in the Intensive-Care Nursery. Berkeley: University of California Press.

ARIAS E. AMCDORMAN, M. F., STROBINO, D. M. and GUYER, B. (2003). 'Annual Summary of Vital Statistics - 2002,' Pediatrics, Vol. 112, No. 6, pp. 1215-1230.

AUTREY, P. K. (2003). The Trouble with Girls: Autoethnography and the Classroom [Dissertation]. Louisiana State University and Agricultural and Mechanical College, The Department of Curriculum and Instruction. <http://etd.Isu.edu/docs/available/etd-0708103-131111/unrestricted/Autrey_dis.pdf> (retrieved July 28,2010$)$.

BOLIG, E. E., BORKOWSKI, J. and BRANDENBERGER, J. (1999). 'Poverty and Health Across the Lifespan,' T. L. Whitman, T. V. Merluzzi and White, R. D. (editors) Life-Span Perspectives on Health and Illness. Mahwah, NH: Lawrence Erlbaum Associates.

BORG, S. and LASKER, J. (1982). When Pregnancy Fails: Coping with Miscarriage, Stillbirth and Infant Death. London: Routledge \& Kegan Paul.

BRAUN, M. J. and BERG, D. H. (1994). 'Meaning Reconstruction in the Experience of Perinatal Bereavement,' Death Studies, Vol. 18, pp. 105-129.

CECIL, R. (1996a). 'Introduction: an insignificant event? Literary and Anthropological Perspectives on Pregnancy Loss,' R. Cecil (editor) The Anthropology of Pregnancy Loss. Oxford: Berg.

CECIL, R. (1996b). 'Memories of Pregnancy Loss: Recollections of Elderly Women in Northern Ireland,' R. Cecil (editor) The Anthropology of Pregnancy Loss. Oxford: Berg.

CHAMBERS, J. M. and CHAN, F. Y. (2004). 'Support for Women/Families after Perinatal Death (Cochrane Review). The Cochrane Library, Issue 1. Chichester, UK: John Wiley \& Sons.

CLANDININ, D. J. and CONNELLY, F.M. (1994). 'Personal experience methods,' in N. Denzin and Y. S. Lincoln (editors) Handbook of Qualitative Research. Thousand Oaks, CA: Sage.

COLEMAN, P. K. (2004). 'The Uniquely Destructive Psychological Experience of Elective Abortion: Comparisons with Other Forms of Perinatal Loss and Delivery of an Unintended Pregnancy,' Association for Interdisciplinary Research in Values and Social Change, Vol. 17, No. 6, <http://www.lifeissues.net/writers/air/air_vol17no6_20041.html> (retrieved July 28, 2010).

CORR, C. A., NABE, C. and COOR, D. M. (1997). Death and Dying, Life and Living. Pacific Grove, CA: Brooks/Cole.

DAVIDSON, D. (2007). The Emergence of Hospital Protocols for Perinatal Bereavement, 1950-2000. Toronto: York University.

DAVIDSON, D. (2008). 'A Technology of Care: Caregiver Response to Perinatal Loss,' Women's Studies International Forum, Special Edition, Women and Technologies of Reproduction, Vol. 31 No. 4, pp. 278284.

ELLIS, C. S. and BOCHNER, A. P. (2006). 'Analyzing Analytic Autoethnography: An Autopsy,' Journal of Contemporary Ethnography, Vol. 35, No. 4, pp. 429-449.

EMKE, I. (1996). 'Methodology and Methodolatry: Creativity and the Impoverishment of the Imagination in Sociology,' Canadian Journal of Sociology, Vol. 21, No. 1, pp. 77-90.

FARR, S. L., SCHIEVE, L. A. and JAMIESON, D. J. (2007). 'Pregnancy Loss among Pregnancies Conceived through Assisted Reproductive Technology, United States, 1999-2002,' American Journal of Epidemiology, Vol. 165, pp. 1380-1388.

FETUS AND NEWBORN COMMITTEE (1983). 'Support for Parents Experiencing Perinatal Loss,' Canadian Medical Associataion Journal, VOL. 129, PP. 335-339.

FINDLAY, D. (1993). 'The Good, the Normal and the Healthy: The Social Construction of Medical Knowledge about Women,' Canadian Journal of Sociology, Vol. 18, N0. 2, pp 115-135.

FOX, R., PILLAI, M., PORTER, H. and Gill, G. (1997). 'The Management of Late Fetal Death: A Guide to Comprehensive Care,' British Journal of Obstetrics and Gynaecology, Vol. 104, pp. 4-10.

HALL, P. M. (2003). 'Interactionism, Social Organization, and Social Processes: Looking Back and Moving Ahead,' Symbolic Interaction, Vol. 26, No. 1, pp. 33-55.

HEALTH CANADA. (2000). Family-Centred Maternity and Newborn Care: National Guidelines. Ottawa: 
Minister of Public Works and Government Services.

HODNETT, E. D., FREDERICKS, S. and WESTON, J. (2010). 'Support During Pregnancy for Women at Increased Risk of Low Birthweight Babies,' Cochrane Database of Systematic Reviews, Issue 6. Art. No.: CD000198. DOI: 10.1002/14651858.CD000198.pub2.

KATZ, J. (2001). 'Introduction.' J. L. Hockey, J., Katz and N. Small (editors) In Grief, Mourning and Death Ritual. Buckingham: Open University Press.

KAVANAUGH, K. and HERSHBERGER, P. (2005). 'Perinatal Loss in Low-income African American Parents,' Journal of Obstetric and Neonatal Nursing, Vol. 34, No. 5, pp. 595-605.

KIRKLEY-BEST, E., KELLNER, K. R. and LADUE, T. (1985). 'Attitudes Toward Stillbirth and Death Threat Level in a Sample of Obstetricians,' Omega, Vol. 15, No. 4, pp. 317-327.

KITSANTAS, P. (2008). 'Ethnic Differences in Infant Mortality by Cause of Death,' Journal of Perinatology, Vol. 28, pp. 573-579.

LANGEN, E. S., SHAHINE, L. K. LORA, K., LAMB, J. D. LATHI, R. B. MILKI, A. A., FUJIMOTO, V. Y. and WESTPHAL, L. M. (2010). 'Asian Ethnicity and Poor Outcomes After In Vitro Fertilization Blastocyst Transfer,' Obstetrics \& Gynecology, Vol. 115, No. 3, pp. 591-596.

LAYNE, L. (1990). 'Motherhood Lost: Cultural Dimensions of Miscarriage and Stillbirth in America,' Women's Health, Vol. 16. No. 3-4, pp. 69-98.

LAYNE, L. (1992). Of Fetuses and Angels: Fragmentation and Integration in Narratives of Pregnancy Loss,' Knowledge and Society, Vol. 9, pp. 29-58.

LAYNE, L. (1996). 'Never Such Innocence Again: Irony, Nature and Technoscience,' in narratives of pregnancy loss, R. Cecil (editor) Comparative Studies in Pregnancy Loss. Oxford: Berg.

LAYNE, L. (1997). 'Breaking the Silence: An Agenda for a Feminist Discourse on Pregnancy Loss,' Feminist Studies, Vol. 32, No. 2, pp. 289-315.

LAYNE, L. (2003). Motherhood Lost: A Feminist Account of Pregnancy Loss in America . New York: Routledge.

LEON, I. G. (1992). 'Perinatal Loss: Choreographing Grief on the Obstetric Unit,' The American Journal of Orthopsychiatry, Vol. 62, pp. 7-8.

LETHERBY, G. (1993). 'The Meanings of Miscarriage,' Women's Studies International Forum, Vol. 16, No. 2, pp. $165-180$.

LETHERBY, G. (2000). 'Dangerous Liaisons: Auto/biography in Research and Research Writing,' G. Treweek and S. Lingkogle (editors) Danger in the Field: Risk and Ethics in Social Research. London: Routledge.

LETHERBY G. (2003). Feminist Research in Theory and Practice. Buckingham: Open University Press.

LOVELL, A. (1983). 'Some Questions of Identity: Late miscarriages, Stillbirth, and Perinatal Loss,' Social Science and Medicine, Vol. 17, No. 11, pp 755-761.

MAGUIRE, M. H. (2006). 'Autoethnography: Answerability/Responsibility in Authoring Self and Others in the Social Sciences/Humanities,' Review Essay: Carolyn Ellis (2004). The Ethnographic I: A

Methodological Novel about Autoethnography [25 paragraphs]. Forum Qualitative Sozialforschung / Forum: Qualitative Social Research, Vol 7, No. 2, Art. 16, <http://nbn-resolving.de/urn:nbn:de:0114-fqs0602165> (retrieved July 20, 2010).

MALACRIDA, C. (1998). Mourning the Dreams: How Parents Make meaning from Miscarriage, Stillbirth and Early Infant Death. Edmonton: Qual Institute Press.

MALACRIDA, C. (1999). Complicating Mourning: The Social Economy of Perinatal Death,' Qualitative Health Research, Vol. 9, No. 4, pp. 504-519.

MITCHINSON, W. (2002). Giving Birth in Canada 1900-1950. Toronto: University of Toronto Press.

PEPPERS, L. G. (1989). 'Grief and Elective Abortion: Implications for the Counselor,' K. Doka (editor) Disenfranchised Grief: Recognizing Hidden Sorrow,. Lexington, MA: Lexington.

PEPPERS, L. G. and R. J. KNAPP, (1980). Motherhood and Mourning: Perinatal Death. New York: Praeger.

RAJAN, L. and OAKLEY, A. (1993). 'No Pills for Heartache: The Importance of Social Support for Women who Suffer Pregnancy Loss,' Journal of Reproductive and Infant Psychology, Vol. 11, pp. 75-87.

REINHARZ, S. (1988). 'What's missing in miscarriage?' Journal of Community Psychology, Vol. 1, pp. 84103 
REINHARZ, S. (2003). 'The Social Psychology of a Miscarriage: An Application of Symbolic Interaction Theory and Method,' M. J. Deegan and M. Hill (editors) Women in Symbolic Interaction. Boston: Allen and Unwin.

ROTHMAN, B. K. (1986). 'Reflections on Hard Work,' Qualitative Sociology, Vol. 9, No. 1, pp. 48-53.

ROTHMAN, B. K. (1987). The Tentative Pregnancy: Prenatal Diagnosis and the Future of Motherhood. New York: Penguin.

ROWE, J., CLYMAN, R., GREEN, C., MIKKELSON, C., HAIGHT, J. and ATAIDE, L. (1987). 'Followup of Families Who Experience a Perinatal Death,' Pediatrics, VOL. 62, pp. 166.

SCHIEVE, L. A., TATHAM, L., PETERSON, H. B., TONER, J. and JENG, G. (2003). 'Spontaneous Abortion Among Pregnancies Conceived Using Assisted Reproductive Technology in the United States,' Obstetrics \& Gynecology, Vol. 101. No.5, pp. 959-967.

SCHREINER, R. L., GRESHAM, E. L. and GREEN, M. (1979). 'Physician's responsibility,' American Journal of Disabled Children, Vol. 133, pp. 723-726.

SIMONDS, W. and ROTHMAN, B. K. (1992). Centuries of Solace: Expressions of Maternal Grief in Popular Literature. Philadelphia: Temple University Press.

SLADE, P. and CECIL, R. (1994). 'Understanding the Experience and Emotional Consequences of Miscarriage-Editorial,' Journal of Reproductive and Infant Psychology, Vol. 12, pp. 1-3.

STRAUSS, A. and CORBIN, J. (1994). 'Grounded Theory Methodology: An Overview,' N. Denzin and Y. S. Lincoln (editors) Handbook of Qualitative Research. Thousand Oaks, CA: Sage.

STRAUSS, A. L., FAGERHAUGH, S, SUCZEK, B. and WIENER, C. (1997). Social Organization of Medical Work. New Brunswick, NJ: Transaction Publishers.

SUDNOW, D. (1967). Passing On: The Social Organization of Dying. Englewood Cliffs, NJ: Prentice Hall.

VAN, P. and MELEIS, A. I. (2003). 'Coping With Grief After Involuntary Pregnancy Loss: Perspectives of African American Women,' Journal of Obstetric, Gynecological \& Neonatal Nursing, Vol. 32, No. 1, pp. 28 -39 .

WALTER, T. (1994). The Revival of Death. London: Routledge.

WATSON J. (1997). 'Unruly Bodies: Autoethnography and Authorization in Nafissatou Diallo's 'De Tilene au Plateau (A Dakar Childhood),' Research in African Literatures, Vol. 28, pp. 33-56.

WEIR, L. (2006). Pregnancy, Risk and Biopolitics: On the Threshold of the Living Subject. London: Routledge.

WHITEHEAD, N. S., CALLAGHAN, W., JOHNSON, C. and WILLIAMS, L. (2009). 'Racial, Ethnic, and Economic Disparities in the Prevalence of Pregnancy Complications,' Maternal Child Health Journal, Vol. 13. No. 2, pp. $198-205$.

WILLIAMS, G. B. (2001). 'Coping with Grief after Involuntary Pregnancy Loss: Perspectives of African American Women,' Journal of Obstetric, Gynecologic \& Neonatal Nursing, Vol. 32, pp. 28-39.

WILLIAMS, G. B. (2006). 'Grief after Elective Abortion: Exploring Nursing Interventions for Another Kind of Perinatal Loss,' Association of Women's Health, Obstetric and Neonatal Nurses, Lifelines, Vol. 4, No. 2, pp. 37-40.

WOLFF, J. R., NIELSON, P. E. and SCHILLER, P. (1970). 'The Emotional Reaction to a Stillbirth,' American Journal of Obstetrics and Gynecology, Vol. 108, pp. 73-77.

ZADORI, J. (2006). 'Assisted Reproductive Technology Pregnancies Were Associated with an Increased Risk of Specific Negative Outcomes,' Evidence-based Obstetrics \& Gynecology, Vol. 8, No. 3, pp. 110111. 